\title{
Research on the Cultural Characteristics of Photography Art
}

\author{
Yongxiao Liu \\ Baoshan University \\ Baoshan, Yunnan Province
}

\begin{abstract}
At present, photography art is gradually integrated into people's daily life in China. Photography is an art that can fully embody people's life concepts. People often express their feelings and experiences from different perspectives and in different forms of photography. The art of photography not only perfectly reflects the author's inner thoughts, but also gives people a strong aesthetic feeling. In the art of photography, form beauty is one of the important components, which plays an important role in improving the artistic sense of photography and expressiveness. Therefore, the paper carries out a detailed study on the modern aesthetic style in the art of photography, and on this basis, it also perform an in-depth discussion of the important role of formal aesthetics in the creation of photography.
\end{abstract}

Keywords-Cultural characteristics; Photography art

\section{INTRODUCTION}

The continuous improvement of material life has caused earth-shaking changes in the aesthetic level, and the pursuit of art is no longer limited to a few people. As a relatively common aesthetic art, photographic art is not only a form of technical expression, but also plays an important role in expressing people's emotions and conveying beauty. In the process of expressing photography art, form beauty is a relatively common form and has unique advantages in expressing the beauty of photography. Under normal circumstances, photography can achieve a kind of resonance with the inner feelings of the audience by means of the form beauty, which makes people think and emotional ups and downs inadvertently.

The name photography comes from the Greek language and directly means the use of light. For its definition, different books have different interpretations. Some say that it is a general term for photography from the beginning of thinking before shooting to shooting and even enlargement. Some say it is the popular art of the scientific era. In "Ci Hai", photography is defined as the process of capturing a scene image with a camera or a movie camera. In today's daily life, people always like to use the camera to record good moments, whether they are partying or traveling. It is no exaggeration to say that photography has become an important existence in people's lives.

\section{THE CULTURAL EMBODIMENT OF PHOTOGRAPHIC ART AESTHETICS IN IDEOLOGY}

The study of photographic art aesthetics belongs to the category of artistic philology, and it is the study of the beauty of art in people's ideology, that is, the problem of photographic works. The first impression of a masterpiece of photography is the beauty of the picture, that is, the visual beauty. Next, in the appreciation of the painting, people will have many associations, and they can experience the artistic conception from the picture. The creator has a creative process before creating the work. What is it to shoot? How to behave? What social value? This series of question marks are filtered in the mind to form a target.

The creative process of photographic art is an aesthetic process. It is the process of the artist's aesthetic consciousness and aesthetic imagination. It is the process of subjective and objective aesthetic feeling, aesthetic norm and aesthetic creation. The motivation and starting point of the photographer's shooting, as well as the ideas to be expressed in the works, that is, the concept and the intention, are the basis for the success of the work. This is the beginning of the aesthetic creation of photography.

The advanced expression of ideology is the key to determining the success of the work. Thought is a leap from perceptual to rational in people's understanding of objective things in social practice. The creative process of artistic works is a leap from perceptual to rational. This process requires photographers to perceive objective reality and think about problems from an aesthetic perspective. Find the beauty and know the beauty of the object being expressed. Through the artist's own cultural accomplishment, his own talents and advanced consciousness, he uses the aesthetic concept, aesthetic standards and aesthetic ability to boldly use his imagination to trigger the emotion, stimulate the creative enthusiasm, and integrate the works in context, artistic conception and context. Create new ideas and new forms of works. The aesthetic creation of photographic art fully embodies the creator's thought ahead consciousness in artistic creation.

Photographic artists use photography tools to frame the beauty, beauty, beauty of nature, and the relationship between people, people and nature, and social changes, all in a single image. It records the development of history, the progress of mankind, the transformation of society, and so on. The pictures 
of these beautiful American moxibustions have solidified the beauty of photography. The object chosen by the photographic artist at the time of creation is nothing more than a person, a thing, a scene, or collectively referred to as a living or inanimate. The state embodied in these objective things is different. How do you highlight their characteristics and differences?

The famous American modern photographer N. Xifu believes that the interpersonal communication process between the photographer and the subject is a highly aesthetic process of the subject. First of all, the photographer should make the object of the intended shooting in the mind and aesthetics. Although they originate from nature and originate from society, the photographs created are not copies of natural and social objects. First of all, we must grasp the personality and characteristics of the object, and fully show the difference and uniqueness between it and other objects. The photographer then mixes with the individual's ideas and emotional activities to extract the essence of art that comes from life above life, so that the perceptual and rational aspects penetrate each other and merge into one. This process is also the process by which the creator combines the advanced ideology with the objective facts. Only the works born through this process can fully reflect the beauty of photographic art.

\section{FORMAL AESTHETICS IN THE ART OF PHOTOGRAPHY}

\section{A. The Sense of Space in Photography}

In the creation of photographic art works, many artists generally express the sense of space in the works through various laws. The sense of space in photographic works is generally achieved through lines and tones. The common expressions are form perspective and air perspective. They are connected and interact with each other. When shooting photographs, they need to The shooting angle is strictly controlled. The line perspective in the sense of space in photography art mainly uses the distance and size relationship generated by the interweaving of lines to reflect its sense of space, while the perspective of the tone is based on the contrast of the shades of the tone to reflect the spatial level. For example, the tone on the photographic works is relatively light, then the scenes depicted are relatively distant scenes; while the shadows are darker, the scenes depicting relatively close are displayed. In addition, when photographers are shooting photographs, they will gradually expand and extend people's sights with rich tone, and people will inadvertently enter more far-reaching space.

\section{B. Dimensional Sense in Photography}

The three-dimensional sense in photography art can be called "volume sense". The existence of three-dimensionality can further deepen the realism and vividness of photography. Most people know that sculpture has high requirements in terms of realism and vividness. However, unlike sculptures, photographic works are mainly shaped by images occupying two degrees of space when expressing stereoscopic effects. The photographer mainly uses the corresponding modeling language to express the three-dimensional space on the basis of the two-dimensional space, which can break the limitation of the three-dimensional sense of the flat shape and maximize the three-dimensional sense. Like the sense of space, the threedimensional sense in photography is also reflected in the light, the tone, the backlight, the side light and the change of the tone all of which have an important influence on the spatial expression of photography. For example, when we take pictures of scenery in our usual life, the landscape pattern that is photographed has a three-dimensional effect, which is caused by the constant changes in light and tone during shooting.

\section{The Dynamics Of Photographic Art Works}

The dynamics of photographic art works as an important part of artistic beauty, but also an important photographic art language. In the art of photography, the existence of dynamics has increased the artistic appeal of photographic art works. In the dynamic performance of photographic art works, mainly through the use of relevant technical techniques and artistic language, through the combination of technical skills and artistic language, create different forms of dynamic images.

\section{CULTURAL CHARACTERISTICS OF PHOTOGRAPHY ART}

\section{A. Photographic Art In Book Binding Design In The Book Design.}

The art of photography is getting more and more attention, especially in the cover design and illustration design of books. The photography technique plays a role that cannot be ignored, adding extra points to the aesthetics of books. The first is the art of photography in the cover design. The purpose of the reader's book purchase is to obtain information with pleasure. For the reader, the focus of the vision is what the book is about. The cover as the image of a book is the key to transmitting information to readers, which makes it interesting to read. It largely determines whether the reader likes the content of the whole book. Adding photographic images to the cover design can quickly catch the reader's eye, and the strong artistic tension has laid a good foundation for the book to enter the reader's heart and win the market opportunity. For example, youth magazines and women's magazines usually choose popular movie stars and models to make covers. The cover of popular science publications often uses pictures of advanced scientific and technological achievements related to nature. The cover of the publication is mainly excellent photography and works of art. For any book form, simply relying on monotonous and boring words to interpret the article will not only reduce the image and interest, but also cause the reader to have visual fatigue and resist reading in spirit. In the current era of highly developed information, such book design forms can no longer meet people's psychological needs and spiritual demands. The realism of photographic art has the characteristics of vividness and vividness. At the same time, it has a certain sense of substitution. It can be applied to the illustration design of the layout, which can echo the content of the text, making it easier for readers to understand the viewpoints and ideas that some texts should explain. 


\section{B. Photography In Print Advertising}

Since the birth of print advertising design, graphic designers have been using traditional painting and image design. With the advancement of society, traditional painting images have been unable to meet the design needs of print advertising. In this context, digital photography has designed high quality for graphic designers with its high definition, high technical content, fast transfer speed, and the technical methods of stacking, contrasting, synthesizing, covering, misalignment and inversion. The excellent works provide a strong backing. Generally speaking, in the design of graphic advertising works, designers often need to combine the two techniques of graphic design and digital photographic image to form the overall work of the advertisement by connecting different forms of the object image, and at the same time, modify the image according to the design requirements. Toning, so as to achieve the second creation of the work, improve the effectiveness and credibility of the advertisement. For example, an advertising design of Sony's color TV sets uses the contrasting techniques in photography to arrange a group of children to play on the TV. The innocent and different children and the TV set a big contrast. The theme of "big" is highlighted, the layout of the screen is vivid and natural, and the taste of life is very beautiful It not only effectively improves the appeal of advertising, but also highlights the theme and promotes the product. It should be noted that in graphic advertising design, creativity is the soul. In such an "attention economy" era, advertisements are numerous, and mediocre works are difficult to stimulate consumers' eyes and nerves. New, strange and special performances are consumers' current pursuits. In order to rob consumers, creativity has become the core of all creations. Therefore, when drawing on the expression techniques of photographic art, graphic designers must break the mindset, cooperate with the photographer's shooting and creative ideas, plus superb PS technology.

\section{Photography Technology in Packaging Design}

The authenticity and recordability of photography can clearly and truly represent the image and characteristics of the product, combined with the rich color level, so that the content in the image is closely related to people's life. More than that, photography can also use the relevant software to adopt a variety of image matching and processing methods, so that the viewer's vision drives a rich association of power, resulting in a wonderful experience beyond the visual. Taking commodity packaging as an example, there are numerous examples of how to reproduce the image of a product through photography. Especially in the packaging design of food, it is not uncommon. In some food packaging designs for desserts and beverages, designers often use photography to perfectly express the luster and taste of things. The intuitive image enhances the appetite of consumers and stimulates the purchase behavior.

In addition to the intuitive image display, in the packaging design of the goods, the designer will also display the goods through more obscure photography techniques. For example, the packaging design of the perfume generally does not directly shoot the perfume itself, but converts the subject into a sexy, beautiful woman to convey the charm and temptation implied in the perfume. This packaging design not only does not deviate from the theme of the perfume, but also It also transcends the direct expression of specific things and can achieve unexpected results.

\section{THE IMPORTANT ROLE OF FORMAL AESTHETICS IN THE CREATION OF PHOTOGRAPHIC ART}

The existence of formal beauty enhances the artistic expression of photographic works. In the process of photographic art creation, the improvement of form beauty mainly depends on the choice of formal expression. To maximize the form beauty of photographic art works, it is necessary to ensure form beauty and photographic content. Harmony and unity, and through the integration of form beauty and the beauty of the charm, the photographic works are harmonious. The content in the photographic works is the most intuitive expression in the photographic art works, but in the photography of the photographic works, in addition to enhancing the emphasis on the photographic content, the photographic artist also needs to ensure the integration of the photographic content and form. The greatest role of Formal Beauty in photographic art works is to support and complement the expressive ability of photographic art, and plays an important role in conveying the content and connotation of art works. Formal beauty enhances the artistic expression of photographic works, realizes the sublimation of photographic art works makes the photographic effect based on reality and transcends reality, and realizes emotional expression and psychological resonance while realizing the reality through photographic works. Different from the photographic content, the content of photographic art works is the soul, the main way to convey the author's thoughts and tap the inner beauty of life. The form of photographic works is the brilliance of photographic works. By means of the form of photographic works, the vividness of the content of photographic works is maximized, and the artistic expression and aesthetic value of the entire photographic art works have an important strengthening effect.

Formal beauty has a greater strengthening effect on the artistic appeal of photographic works. Capture the most aesthetically photographic elements, and then effectively filter the elements that are not related to the shooting, and perfectly control and embody the focus of the entire photographic art work. Generally speaking, a good photographic work needs to have a unique form of beauty, and then fully express the content to be expressed through the unique form of beauty, so that people can fully understand and understand the content and emotions that the photographic art works should express. The beauty of the role of photographic art is characterized by purpose and creativity. Among them, the purpose of form beauty refers to the photographic artist's use of form beauty to refine and process many photographic elements in photographic works, in order to sublimate and highlight the connotation of photographic art works, and fully reflect the tension of photographic works. The creativity of photographic art works requires the support of formal beauty, that is, the lack of formal beauty in photographic art works lacks creativity, because the lack of formal beauty affects the artistic performance of the works. 
Formal beauty realizes the profound communication of the emotions and connotations of photographic works. In the field of art, photographic works are an important form of the inner feelings of photographic artists. The existence of formal beauty in photographic works is also a relatively important driving force. . With the application of Form Beauty in photographic art works, photographic artists express their own emotions and the connotation of their works, but in the process of creation, it is necessary to strengthen the application of innovative thinking to ensure that photographic art works keep pace with the development of the times. . Usually, if the photographic art works are only used to copy and paste the real life, then the meaning of the photographic art works is completely lost.

\section{CONCLUSION}

In order to further gain people's recognition, photographic art works must perfect and sublimate the content and form of the works. First of all, through the perfection of content and form, embody life, feel life, and use the application of form beauty in photographic art creation to realize the combination of love and scenery. Secondly, it enhances the artistic appeal and expressive power of photographic art works, thus integrating and reflecting people's emotions and ideological connotations, giving people an immersive artistic conception. Finally, through the appreciation of photographic art works to achieve physical and mental washing and sublimation.

\section{REFERENCES}

[1] Geng Hongjie. The Application of Chinese Traditional Culture Elements in Paintings of Paintings[J]. Camera,2018,0(8):35-37.

[2] Chen Fuli (figure), Chen Bo. Huaguang Collection Boutique [J]. Strait Film Art, 2018, 0 (2).

[3] Lu Bin. Lang Jingshan highlights photography art exploration [J]. Tomorrow fashion, 2018, 0 (6): 104-104.

[4] Wang Zhi. On the economic benefits and social and cultural values brought by basketball [J]. Hebei Agricultural Machinery, 2018, 0 (9): 48-48.

[5] Yang Wei [1]. Exploring the relationship between exercise and intestinal microflora [J]. Science and Technology Journal (electronic version), 2018, 0 (24): 284-285.

[6] Michael Jordan is not a fiction [J]. NBA special issue, 2018, 0 (18): 8287.

[7] Zhang Aiping. Analysis of outdoor sunshine special activities in kindergartens $[\mathrm{J}]$. Educational Practice and Research: Theoretical Edition (C), 2018, 0 (9): 52-53. 